\title{
The neutral condition in sentence context experiments: Empirical studies
}

\author{
RICHARD F. WEST \\ James Madison University, Harrisonburg, Virginia \\ and \\ KEITH E. STANOVICH \\ Oakland University, Rochester, Michigan
}

\begin{abstract}
Several experiments are reported in which comparisons were made between different neutral conditions that have been used in sentence context experiments. There was a tendency for the neutral sentence fragment "the next word will be" to yield faster word-naming times than three other neutral conditions ("they said it was the," randomized strings of words, and strings of Xs). The latter three conditions tended to yield roughly similar naming times. Across the several experiments, all four of these neutral conditions tended to show either facilitation-dominant patterns or roughly equal amounts of facilitation and inhibition. Inhibition dominance was never obtained. These experiments may be useful in giving some indication of the probable empirical consequences of making different conceptual decisions regarding the neutral condition in a particular experiment.
\end{abstract}

Many studies of sentence context effects on word recognition have attempted to separate facilitation effects from inhibition effects to make certain theoretical distinctions (Becker, 1980, 1985; Eisenberg \& Becker, 1982; Fischler \& Bloom, 1979, 1980, 1985; Forster, 1981; Stanovich \& West, 1983; West \& Stanovich, 1982, 1986). Of course, it has been recognized that the accuracy of this separation depends on the adequacy of the neutral condition used in the experiment. Despite the frequency with which this caveat has been raised and despite Jonides and Mack's (1984) elegant conceptual analysis of the neutral condition in priming experiments, investigators rarely have checked the convergent validity of the neutral condition they have chosen by comparing it directly with other plausible choices. Only a few such comparisons have been published (e.g., Fischler \& Bloom, 1979; Forster, 1981; Schuberth \& Eimas, 1977; Stanovich \& West, 1983). In the experiments reported here, we made several such comparisons. We employed the difficult target words from the set of sentence contexts that we have used in several previous experiments. These words show larger contextual effects than words that are easier to recognize, and thus they maximize the chances of observing differences between alternative neutral conditions. In previous experiments employing the neutral condition "they said it was the," these stimuli have shown a pattern of facilitation dominance, although small amounts of inhibition have

This research was supported by National Science Foundation Grant BNS80-20594 to Keith E. Stanovich and by a James Madison University faculty research grant to Richard F. West. Requests for reprints should be sent to Keith E. Stanovich, Department of Psychology, Oakland University, Rochester, MI 48063. often been observed with them (Stanovich \& West, 1983; West \& Stanovich, 1982).

\section{EXPERIMENT 1}

In Experiment 1 three neutral conditions were compared. One was the sentence fragment "they said it was the" that we have used in previous research. The second was the fragment "the next word will be," which was used by McClelland and O'Regan (1981) and by us in previous comparisons (Stanovich \& West, 1983). The third neutral condition was composed of random strings of words. Forster (1981) argued that fragments such as "they said it was the" overestimate neutral times (thereby underestimating inhibition), whereas random strings yield faster times. Experiment 1 allowed a direct empirical test of this conjecture.

\section{Method}

Subjects. The subjects were 24 undergraduate volunteers recruited through a psychology department subject pool.

Stimuli and Apparatus. The 96 sentence contexts and corresponding difficult target nouns presented in Appendix A of Stanovich and West's (1981) paper were used as stimuli. These stimuli were constructed so that their last two words were the words "the" and a target noun that was moderately predictable from the preceding context (e.g., "the skier was buried in the avalanche"). These contexts were the congruous contexts. The 96 contexts were organized into 48 pairs (e.g., "the skier was buried in the" was paired with "the bodyguard drove the"). Incongruous sentences were formed by combining target words from one member of the pair with the context of the other (e.g., "the bodyguard drove the avalanche"'). Three neutral context conditions were created by presenting "they said it was the" (termed the "theysaid" neutral condition), "the next word will be" (termed the "thenext" neutral condition), or random orderings of words (termed the "random" neutral condition) prior to a target. The stimuli for the random condition 
were constructed by randomly rearranging the words from the corresponding incongruous sentence contexts.

The stimuli were presented on a CRT monitor under the control of an Apple II microcomputer. A Mountain Hardware clock and a voiceactivated relay were interfaced with the computer to enable the collection of the naming times. When the target word was presented, it was in the position it would have occupied had the context been continued.

Procedure. The words in a context were presented sequentially from left to right across the monitor. A new word appeared every $400 \mathrm{msec}$, and each word stayed on the screen as others were added. A plus sign appeared on the screen before the onset of the first context word. The plus sign indicated the position on the screen where the first letter of the target would appear. When all the words of the context and the target were displayed (target onset was $400 \mathrm{msec}$ after the onset of the last word of the context), the location that had been occupied by the plus sign was occupied by the first letter of the target. The subjects were instructed to read silently each word of the context as it appeared and then read the target word aloud when it appeared. The subject's reaction time in milliseconds was displayed in the upper left corner of the display after each trial.

Each subject received a random ordering of 12 practice trials, consisting of 2 trials given under each of the three neutral context conditions and 3 trials given under the congruous and incongruous context conditions. Following the practice trials, each subject received a random ordering of 72 experimental trials, consisting of 8 trials given under each of the three neutral context conditions and 24 trials given under the congruous and incongruous context conditions. In the experimental trials, each subject saw a subset of 72 of the total population of 96 possible targets. The assignment of targets from the total population was counterbalanced across subjects so that each target was read equally often under the congruous, neutral, and incongruous conditions, and, within the neutral condition, equally often under the theysaid, thenext, and random conditions. No subject saw the same target or context more than once in the course of the experiment. When contexts were used in either incongruous or random context trials, the deleted target words from the original sentences were never seen by the subject.

\section{Results}

The mean reaction times and the mean percentages of subject errors for all experimental conditions are displayed in Table 1. This table also contains the data from all subsequent experiments.

The mean reaction time obtained under the thenext neutral condition $(M=580 \mathrm{msec})$ was significantly faster than those obtained under the theysaid neutral $(M=$ $620 \mathrm{msec})$ and the random neutral $(M=621 \mathrm{msec})$ conditions $[t(23)=2.19, p<.05$, and $t(23)=3.09$, $p<.01$, respectively]. The congruous condition was responded to significantly faster than were the theysaid, thenext, and random conditions $(p<.001, .01$, and .001 , respectively). The mean reaction time in the incon-

Table 1

Mean Reaction Times (in msec) and Mean Percentages of Errors (\%E) for Experiments 1 to 5

\begin{tabular}{|c|c|c|c|c|c|c|c|c|c|c|}
\hline \multirow{3}{*}{$\begin{array}{l}\text { Context } \\
\text { Condition }\end{array}$} & \multicolumn{10}{|c|}{ Experiment } \\
\hline & \multicolumn{2}{|c|}{1} & \multicolumn{2}{|c|}{2} & \multicolumn{2}{|c|}{3} & \multicolumn{2}{|c|}{4} & \multicolumn{2}{|c|}{5} \\
\hline & $M$ & $\% \mathrm{E}$ & $M$ & $\% \mathrm{E}$ & $M$ & $\% \mathrm{E}$ & $M$ & $\% \mathrm{E}$ & $M$ & $\% \mathrm{E}$ \\
\hline Theysaid & 621 & 1.0 & 632 & 2.1 & 581 & 0.8 & 614 & 2.1 & 587 & 2.3 \\
\hline Thenext & 580 & 2.6 & 593 & 1.4 & 591 & 1.3 & 592 & 1.0 & 581 & 2.3 \\
\hline Random & 621 & 2.1 & 611 & 1.7 & 616 & 1.6 & - & - & - & - \\
\hline Xs & - & - & - & - & - & - & - & - & 593 & 1.4 \\
\hline Congruous & 536 & 1.0 & 542 & 1.2 & - & - & 554 & 0.6 & 555 & 1.1 \\
\hline Incongruous & 603 & 2.3 & 602 & 1.9 & - & - & 615 & 1.7 & 619 & 1.9 \\
\hline
\end{tabular}

gruous condition did not differ significantly from that of any neutral condition. Thus, all three neutral conditions displayed facilitation dominance, although the thenext condition was the fastest of the three. The results of an items analysis mirrored the subjects analysis in all critical aspects.

\section{EXPERIMENT 2}

Because the words in the random condition of Experiment 1 were words from the same sentence, there is the possibility that semantic relationships between these randomized words could produce unusual processing sets that generated expectancies not typical of a purely random word list. Put simply, perhaps the subjects recognized the random contexts as rearrangements of the meaningful sentence fragments. Experiment 2 eliminated this possibility. It was identical to Experiment 1 except that associations between words in the random condition were removed.

\section{Method}

The subjects were 36 undergraduate volunteers recruited through a psychology department subject pool. The stimuli, apparatus, and procedure were the same as in Experiment 1, except that in the random condition the main content word of each random context was replaced by the main content word from another random context. (Across the 96 contexts, the main content word was a noun in 76 cases and a verb in 20 cases.)

\section{Results}

The mean reaction time obtained in the thenext neutral condition $(M=593 \mathrm{msec})$ was significantly shorter than that obtained in the theysaid condition $[M=632 \mathrm{msec}$, $t(35)=2.42, p<.05$ ], but it did not differ significantly from the mean reaction time in the random condition $(M$ $=611$ ). The congruous condition yielded a mean reaction time that was significantly shorter than that of the theysaid, the thenext, or the random conditions ( $p s<.001)$. Since none of the neutral conditions was responded to significantly faster than the incongruous condition, the patterns were again facilitation dominant for all three neutrals. The results of an items analysis mirrored the subjects analysis in all critical results. The results of Experiments 1 and 2 were thus similar. The thenext condition was fastest in both experiments, and in neither experiment was the random condition significantly faster than the theysaid condition.

\section{EXPERIMENT 3}

In Experiment 3 the three neutral conditions were compared directly, without the interspersed congruous and incongruous trials.

\section{Method}

The subjects were 16 undergraduate volunteers recruited through a psychology department subject pool. The stimuli, apparatus, and procedure were the same as in Experiment 2, except that the congruous and 
incongruous conditions were dropped and the number of presentations of the theysaid, thenext, and random conditions was increased to 4 practice and 24 experimental trials each.

\section{Results}

The only significant difference between the means of the three neutral conditions was that the theysaid condition was responded to significantly faster than the random condition $[t(15)=2.24, p<.05]$. The results of the items analysis were parallel to those of the subjects analysis, except that the thenext condition was responded to significantly faster than the random condition $[t(95)=$ $2.54, p<.05]$. These two conditions were not significantly different in the subjects analysis $[t(15)=1.88, p$ $=.08$ ]. Experiment 3 thus did not replicate the tendency, displayed in Experiments 1 and 2, for the thenext condition to be responded to faster than the theysaid condition. However, Experiment 3 was consistent with Experiments 1 and 2 in indicating that the theysaid condition was not responded to more slowly than the random condition, contrary to Forster's (1981) hypothesis.

\section{EXPERIMENT 4}

The thenext condition was responded to significantly faster than the theysaid condition in the experiments where congruous and incongruous trials were included, but not where these conditions were excluded. Experiment 4 compared only these two neutrals (the random condition was dropped) with congruous and incongruous trials interspersed.

\section{Method}

The subjects were 36 undergraduate volunteers recruited through a psychology department subject pool. The stimuli, apparatus, and procedure were the same as in Experiment 1, except that the random condition was dropped and the number of trials in the theysaid and thenext conditions was correspondingly increased.

\section{Results}

The mean reaction time in the thenext condition was significantly shorter than that obtained from the theysaid condition in the items analysis $[t(95)=2.30, p<.05]$, but not in the subjects analysis $[t(35)=1.57, p=.12]$. The thenext condition displayed significant inhibition in an items analysis $[t(95)=2.06, p<.05]$, but not in the subjects analysis $[t(35)=1.73, p=.09]$. Experiment 4 thus confirmed (in the items analysis) the tendency for the thenext condition to be responded to faster than the theysaid condition, and thus to be more prone to display more inhibition. In fact, unlike Experiments 1 and 2, this neutral condition displayed significant inhibition (in the items analysis) in Experiment 4. However, even the thenext condition displayed more facilitation than inhibition.

\section{EXPERIMENT 5}

Some previous sentence context experiments have used strings of Xs as the neutral condition (Fischler \& Bloom,
1979, 1985; Kinoshita, Taft, \& Taplin, 1985). In Experiment 5 this neutral condition was compared with the thenext and the theysaid conditions.

\section{Method}

The subjects were 72 undergraduate volunteers recruited through a psychology department subject pool. The stimuli, apparatus, and procedure were the same as in Experiment 1, except that the random condition was replaced by a new neutral condition that consisted of a string of Xs and spaces (XX XXXXX XX XXXXX XXXXX XXXX). This particular string, which mimics a six-word context, was used by Kinoshita et al. (1985).

\section{Results}

The mean reaction times obtained in the three neutral conditions did not differ significantly. All three neutral conditions displayed significant facilitation (all $p \mathrm{~s}<.001)$ and significant inhibition $(p<.001, .001$, and .05 , for the theysaid, thenext, and Xs conditions, respectively). The results of an items analysis mirrored the subjects analysis in all critical aspects. Unlike Experiments 1, 2, and 4, all three neutral conditions displayed roughly equal amounts of facilitation and inhibition.

\section{GENERAL DISCUSSION}

The results of these five experiments provide rough empirical estimates of the magnitudes of the differences that we might expect between alternative neutral conditions used in sentence context experiments. With the particular neutral conditions used here, there seems to be a relatively consistent trend for the thenext condition to be responded to most quickly of the four conditions. In four out of five comparisons it was responded to faster than the theysaid condition, in three out of three comparisons it was responded to faster than the random condition, and in a single comparison it was responded to faster than strings of Xs. There was no tendency for the theysaid condition to be responded to more slowly than random words or strings of Xs. Across the several experiments, all four of these neutral conditions tended to show either facilitation-dominant patterns or roughly equal amounts of facilitation and inhibition. Inhibition dominance was never obtained.

If Forster's (1981) recommendation to choose the fastest condition as the most appropriate neutral condition is correct, then thenext is the condition of choice. However, in many cases, such a simple quantitative criterion probably will not suffice. Instead, the appropriateness of a particular condition will depend on the experimental design and on the question being addressed (see Jonides \& Mack, 1984; Stanovich \& West, 1983; West \& Stanovich, 1986). In some cases, the choice will be a conceptually difficult one to make. In such situations, data on the empirical comparability of different conditions, such as those presented here, may be of practical use in giving some indication of the probable empirical consequences of different conceptual decisions. These experiments also give some indication of the variability of the differences between these neutral conditions from experiment to experiment.

\section{REFERENCES}

BeCKer, C. A. (1980). Semantic context effects in visual word recognition: An analysis of semantic strategies. Memory \& Cognition, 8 , 493-512.

BECKER, C. A. (1985). What do we really know about semantic context effects during reading? In D. Besner, T. Waller, \& G. MacKinnon (Eds.), Reading research: Advances in theory and practice (Vol. 5, pp. 125-166). New York: Academic Press.

EISENBe RG, P., \& BeCKer, C. A. (1982). Semantic context effects in visual word recognition, sentence processing, and reading: Evidence for semantic strategies. Journal of Experimental Psychology: Human Perception \& Performance, 8, 739-756.

FisCHLER, I., \& BLOOM, P. (1979). Automatic and attentional processes 
in the effects of sentence contexts on word recognition. Journal of Verbal Learning \& Verbal Behavior, 18, 1-20.

Fischler, I., \& BloOM, P. (1980). Rapid processing of the meaning of sentences. Memory \& Cognition, 8, 216-225.

FischleR, I., \& BloOM, P. (1985). Effects of constraint and validity of sentence contexts on lexical decisions. Memory \& Cognition, 13, 128-139.

Forster, K. I. (1981). Priming and the effects of sentence and lexical contexts on naming time: Evidence for autonomous lexical processing. Quarterly Journal of Experimental Psychology, 33A, 465-495.

JoNides, J., \& MACK, R. (1984). On the cost and benefit of cost and benefit. Psychological Bulletin, 96, 29-44.

Kinoshita, S., TAFT, M., \& TAPlin, J. E. (1985). Nonword facilitation in a lexical decision task. Journal of Experimental Psychology: Learning, Memory, \& Cognition, 11, 346-362.

McClelland, J. L., \& O'ReGan, J. K. (1981). Expectations increase the benefit derived from parafoveal visual information in reading words aloud. Journal of Experimental Psychology: Human Perception \& Performance, 7, 634-644.
Schuberth, R. E., \& Eimas, P. D. (1977). Effects of context on the classification of words and nonwords. Journal of Experimental Psychology: Human Perception \& Performance, 3, 27-36.

Stanovich, K. E., \& WeSt, R. F. (1981). The effect of sentence context on ongoing word recognition: Tests of a two-process theory. Journal of Experimental Psychology: Human Perception \& Performance, 7, 658-672.

Stanovich, K. E., \& West, R. F. (1983). On priming by a sentence context. Journal of Experimental Psychology: General, 112, 1-36.

West, R. F., \& Stanovich, K. E. (1982). Source of inhibition in experiments on the effect of sentence context on word recognition. Journal of Experimental Psychology: Learning, Memory, \& Cognition, 8, 385-399.

West, R. F., \& Stanovich, K. E. (1986). Robust effects of syntactic structure on visual word processing. Memory \& Cognition, 14, 104-112.

(Manuscript received for publication May 30, 1987.) 